\title{
The CDIO Reform Led by Skill Competition in Higher Vocational Colleges
}

\author{
Xinyao Zou ${ }^{1, a^{*}}$, Yating Liu ${ }^{1, b}$, Yanli Zhang ${ }^{1, c}$ and Hengchou Han ${ }^{1, d}$ \\ Mechanical and electrical department, Guangdong AIB Polytechnic College, Guangzhou, China \\ amadelinexy@163.com, bytl@gdaib.edu.cn, cylz@gdaib.edu.cn, dhhh@gdaib.edu.cn
}

Keywords: CDIO; Higher vocational education; Skill competition

\begin{abstract}
In order to cultivate comprehensive occupation ability of higher vocational students, this paper explores a kind of higher vocational education "CDIO project driven" teaching reform mode led by occupation skill competition. The model integrates the knowledge, skills and qualities required in the skills competition into the normal professional teaching curriculum system, and take the evaluation criteria of skill competition as one of the means to assess the level of personnel training. Through this CDIO reform, the students not only can master the professional skills, but also have certain innovation ability, ability to analyze problems, problem-solving skills, teamwork ability, self-learning ability and comprehensive occupation ability.
\end{abstract}

\section{Introduction}

The CDIO teaching model is a new engineering education mode based on the engineering environment to learn, which was developed in October 2000 by the Massachusetts Institute of Technology (MIT) and the Swedish Charles Moss Industrial University [1,2]. CDIO contains four aspects: conceive, design, implement and operate. Skills competition is a comprehensive design project. Students can improve the ability of logical thinking ability and the analysis question, solve the problem of students, troubleshooting by participating in the competition. Through CDIO reform, students can cultivate their independent thinking ability and the spirit of unity and cooperation, and promote their innovation consciousness and innovation ability.

Section 2 details the characteristics of CDIO reform led by skill competition. Conclusion remarks are drawn in section 3 .

\section{CDIO Reform Led by Skill Competition}

Skills competition is a comprehensive design project, in order to achieve good results in the competition, students must have a solid foundation. Therefore, it is necessary to establish the corresponding personnel training mode for the overall planning and guidance. In order to better carry out skills competition training, this paper explores the reform of CDIO, which is divided into four parts, as shown in Figure 1, including teaching reform based on student-centered, establishing innovation laboratory, strengthen training before competition and selecting participator.

Teaching Reform Based on Student-Centered. In order to achieve the goal of cultivating innovative talents, we should change the traditional teaching concept centered on teachers' teaching, and adopt the student centered teaching method. Teachers should consciously integrate innovation consciousness into the teaching process, and cultivate students' autonomous learning ability. Different teaching methods can be adopted according to the difference between the basic courses and the core courses.

For the basic skills courses, teachers should change the proportion between theoretical knowledge and experiment. In the learning process of these courses, teachers provide detailed guidance, guide the 


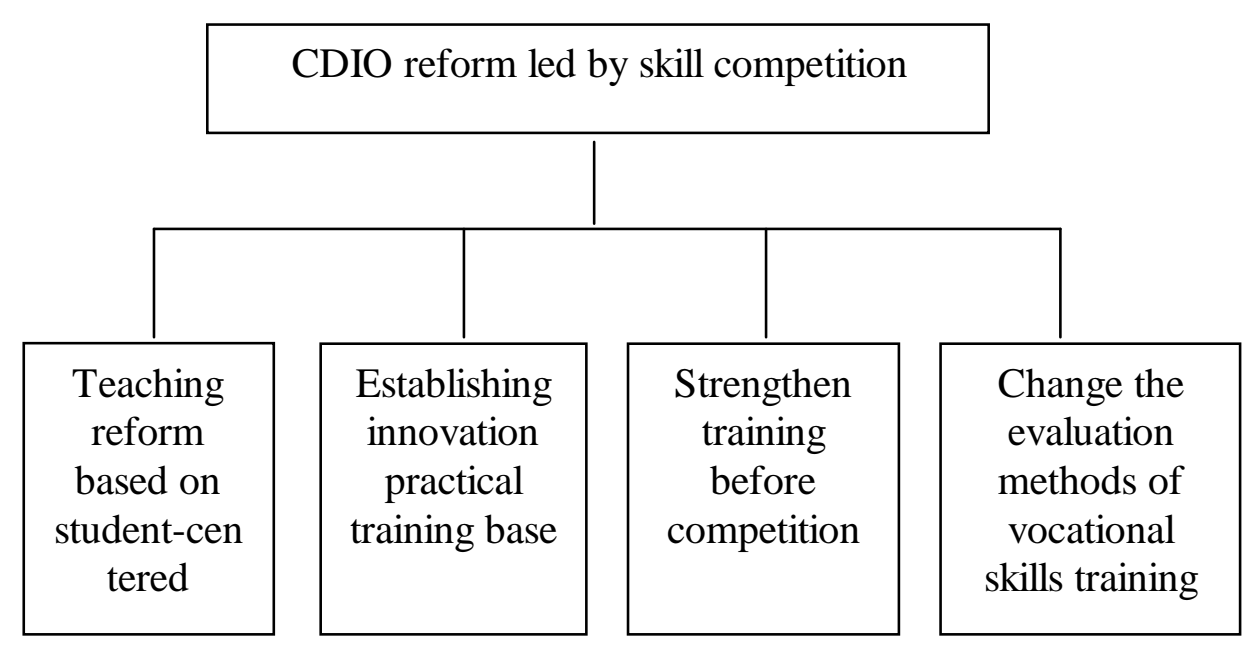

Figure 1. CDIO reform led by skill competition

students to master the necessary skills, ability to enable students to identify components, and learn to use the basic knowledge of welding technology, electronic equipment, installation and commissioning to master basic electronic circuit, electronic products production technology and processes, skilled use of electronic circuit board design software, PCB board drawing plate. At the end of the course, teacher should organize an electronic production contest. Each student is required to design and manufacture one or more pieces of electronic products, including the purchase of components, the production of printed circuit boards, electronic components of the welding, circuit debugging, production instructions. In addition, it's preferred to organize relevant teachers to evaluate the students' work in order to stimulate students' interest and enthusiasm. Through the training, students not only consolidate the basic knowledge of analog circuits and digital circuits, but also master the steps and methods of making simple circuits.

As for the MCU and programmable logic devices and other professional core courses, we use the project teaching method based on student-centered, as shown in table 1. In the project teaching method [3-6], highlight the "learning to do, do middle school" training, each project in accordance with the easy, medium and high degree of difficulty is divided into different modules. In the primary stage of the module, teachers provide detailed guidance, guide the students to complete the project; in the intermediate module stage, with preliminary project planning ability in students, teachers simplified guidance, cultivate students' ability to work independently; in advanced module stage, teachers do not provide guidance, students can independently complete the project.

Table 1 Project teaching method based on student-centered

\begin{tabular}{cc}
\hline module & \multicolumn{1}{c}{ Teaching method } \\
\hline Primary module & Teachers provide detailed guidance \\
Medium module & Teachers provide simplified guidance \\
Intermediate module & Teachers do not provide guidance \\
\hline
\end{tabular}

Establishing Innovation Practical Training Base. Practical training base is a platform for vocational colleges to train students' practical ability and cultivate students' quality. At present, there are many problems, such as high repetition rate, low utilization rate, backward equipment level, and so on, which are the obstacles and bottlenecks that restrict the exertion of the training base and the formation of vocational education characteristics. The cooperation between schools and enterprises can make up for the shortage of the training base construction of the wool industry, become the basic platform to train students and cultivate students' professional quality, and provide a platform for improving students' skill level. Vocational colleges should be based on the actual situation, focus on human, financial and material resources to build a special training room, training workshop. At the same time actively introduce enterprise funds, equipment and production lines, strengthen the training base construction 
strength, and through the provision of training venues and teachers, cooperation in $\mathrm{R} \& \mathrm{D}$ and production way for enterprises to realize the exchange of resources, benefits and win-win. On the other hand, in response to a variety of skills competition to provide services. Training base construction must follow the principle of simulation, advanced and universal, so that training facilities closer to the actual production, training space closer to the corporate environment. Through the teaching and factory closely together, we can provide students a complete factory environment, and truly realize the seamless connection between learning and employment.

Strengthen Training Before Competition. Pre competition training is the key to achieve good achievements in the skills competition. In the training process, teachers create electronic skills competition of real environment, pay attention to students' practical ability, analysis ability and troubleshooting training skills, enable students independently complete the design and production of electronic circuit module and the whole system. Teachers can arrange the pre competition training before the competition to practice training. Through planned training, from the shallower to the deeper, students are required to complete the design task related within the prescribed period of time. And with the deepening of the training, teachers gradually deepen the difficulty of the test, shorten the competition time, the introduction of competition mechanism to adjust, to promote the rapid improvement of students' practical ability.

Change the Evaluation Methods of Vocational Skills Training. At present, the evaluation system of higher vocational colleges is generally accepted by the evaluation and reward system of undergraduate elite education, and the evaluation mainly stays in the study of the mastery of knowledge, which is not conducive to the cultivation of students' ability. In the process of training students, vocational skills competition is only a means, the purpose is to promote vocational skills training through evaluation, and promote the improvement of students' Vocational skills. Therefore, in order to establish the new model of ability evaluation standard, the school can change the original scholarship, which separated the original rewards into two parts, $50 \%$ of them are used to reward outstanding students in the assessment of theoretical knowledge, and the other is the special fund of the vocational skills competition, which rewards students who have achieved outstanding results and outstanding performance in the skills competition. In order to improve the scale and quality of vocational skills competition, the competition should not be qualified to qualify, so that everyone can participate in the competition.

\section{Conclusion}

The vocational skills competition has the characteristics of market orientation, pattern diversity, organization standardization and operation. In order to promote the vocational school to deepen the teaching reform, improve the quality of education and the level of education put forward new requirements, it is necessary to strengthen the cooperation between school and enterprise, and deepen the reform of CDIO, as an important means to do the characteristics of Vocational education.

\section{Acknowledgements}

Supported by Higher Vocational Education Reform Project of Guangdong, China under grant No.201401155. Teaching reform project of Guangdong Skills Competition Teaching Steering Committee of Guangdong, China under grant No. 201509002.

\section{References}

[1] Feng Zhou. Discussion of training experience of National undergraduate electronic design contest. SCTANCA\&TACHN.2009,35:6.

[2] Jing-ping LI, Min-hui Chang.Thinking of Bringing up Innovative Person with Ability by Undergraduates Electronic Design Competition. JOURNAL OF EEE.2007,29(2):74-76. 
[3] Hai-lan Pan, An-bao Wang, Ji-hong Yann. Projected Teaching Method for XML Technology Course Design. The Second International Workshop on Education Technology and Computer Science. Wuhan, China.6-7 March 2010.vol.1:390-393.

[4] Pavasovic, A. Popovic, J. Small budget, project based, VLSI design teaching method.24th International Conference on Microelectronics. NIS, SERBIA AND MONTENEGRO, 16-19 May 2004.vol, 2: 765-768.

[5] Long-jun Huang, Li-ping Dai, Bin Guo. The application of project management in project-driven teaching model.2010 2nd International Conference on Education Technology and Computer. Shanghai, China, 22-24 June 2010.vol.4:91-94.

[6] Ming-jun Xin, Zhen-hua Qin, Lip-eng Wang. Research on Project-Driven Teaching Method Innovation on Post-Graduate Professional Courses. International Forum on Computer Science-Technology and Applications. Chongqing, China. 25-27 Dec. 2009.vol.3: 127-130. 